\title{
Impact of Biases in Gridded Weather Datasets on Biomass Estimates of Short Rotation Woody Cropping Systems
}

Running title: Gridded weather data \& SRWC biomass estimates

Varaprasad Bandaru ${ }^{1}$, Yu Pei ${ }^{1}$, Quinn Hart $^{2}$, and Bryan M. Jenkins ${ }^{3}$

${ }^{1} U C$-Davis Energy Institute, University of California, Davis, CA; ${ }^{2}$ Department of Land, Air, and Water Resources, University of California, Davis, CA; ${ }^{3}$ Department of Biological and Agricultural Engineering, University of California, Davis

Keywords: biomass, gridded weather data, spatial modeling, hybrid poplar, uncertainty, 3-PG model, PRISM, NLDAS, NARR, Daymet

Type of the Paper: Original Research Article

1

(C) 2016. This manuscript version is made available under the Elsevier user license http://www.elsevier.com/open-access/userlicense/1.0/ 


\section{Abstract}

Short rotation woody crops (SRWC) systems continue to be investigated as energy crops for a range of energy products including liquid biofuels and electricity. To understand their market potential and economic viability, regional biomass yield and production estimates are used as primary inputs. Biomass is generally estimated using growth models which often utilize gridded weather datasets when implemented for regional simulations. With such models, the accuracy of weather data will affect the uncertainty of estimated biomass and subsequent bioenergy analyses. This study evaluates the biases in weather variables of commonly used high resolution gridded datasets including PRISM, Daymet, NARR, and NLDAS in comparison with observed weather at five flux tower stations. Further, impacts of inaccuracies in gridded data sources on biomass estimates of SRWC hybrid poplar was investigated at site and regional levels using a version of the 3-PG growth model modified to model production with multiple harvests through coppicing or periodic cutting of the trees with regrowth from the roots.

Results suggest that weather variables in all gridded datasets are characterized by some degree of bias leading to considerable bias in biomass estimates, in some cases up to $45 \%$. PRISM and Daymet were shown to have lower uncertainty in most of the weather variables, likely due to their higher spatial resolution and higher dependency on station weather. Site level simulations indicate that relative to the reference biomass estimates based on actual weather measurements, NARR data yielded 4.1 $\mathrm{Mg} \mathrm{ha}^{-1} \mathrm{y}^{-1}$ higher biomass while NLDAS, Daymet, and PRISM resulted in 3.3, 1.2 and $0.3 \mathrm{Mg} \mathrm{ha}^{-1} \mathrm{y}^{-1}$ lower biomass. Regional simulations suggest that total biomass varied substantially with gridded data sources ranging between 47.4 and $58.3 \mathrm{Tg}$ on the croplands and rangelands in the region (Columbia Plateau), which subsequently led up to $23 \%$ variation in the estimate of poplar based jet fuel production from the SRWC resource. 
Therefore, findings of this study reinforce the need to account for uncertainties in biomass estimates introduced by biases in gridded weather when modeling bioenergy production.

\section{Introduction}

Biomass from short-rotation woody crops (SRWC) such as hybrid poplar (Populus spp., willow (Salix spp.), eucalyptus (Eucalyptus spp.) has been investigated as a promising renewable feedstock resource for the production of bioenergy and other bio-based products (Hinchee et al., 2009). SRWC have many attributes that make them attractive for biomass cropping systems including their fast growth, coppicing ability for some species (i.e. their ability to resprout after harvest), ease of propagation, adaptability to various climate and soil conditions, and utility in helping to restore soil quality (Sims and Venturi, 2004; Rockwood et al., 2004; Hinchee et al., 2009). At present, these systems are mostly pre-commercial as energy crops, and there have been many regional-scale feasibility studies investigating the technical, economic, environmental and, social aspects associated with deploying SRWC systems at multiple scales (Dubuisson and Sintzoff, 1998; Hoffmann and Weih, 2005; Volk et al., 2006; Buchholz and Volk, 2011; Miao et al., 2012; Bandaru et al., 2015). The common primary inputs used in most of these studies are the estimates of potential biomass production. Biomass estimates are required to determine net energy potential under different management systems and technologies (Schmer et al., 2008; Bandaru et al., 2013), economic costs associated with biomass collection and supply to refineries (Downing and Graham, 1996; Hoogwijk et al., 2009), net economic benefits of feedstock production (Allen et al., 2013), cost competitiveness with current cropping systems (De La Torre Ugarte and Ray, 2000; McLaughlin and Kszos, 2005; English et al., 2006;

Egbendewe-Mondzon et al., 2011), and carbon sequestration potential (Deal et al., 2014). Biomass yields are also used as key inputs in system optimization models to identify cost- 
effective biomass supply locations and to develop sustainable supply chains for the production of bioenergy and other products (Parker et al., 2010; Bandaru et al., 2015). In addition, regional simulated yields are often used to identify areas for more intensive study and planting of actual field trials.

Forest growth models or modifications of them are typically applied to determine potential regional SRWC biomass estimates under different management conditions (Deckmyn et al., 2004; Amichev et al., 2011; Tallis et al., 2013; Hart et al., 2015). These models use principles of plant growth and their interactions with weather, soil and management to predict biomass yields. For model implementation, various input variables (e.g. soil characteristics, plant parameters, weather variables) are required, among which weather factors have the most significant impact on model estimates. Weather factors influence various biophysical processes (e.g. transpiration, photosynthesis) that drive plant growth and development (Hoogenboom, 2000). Weather fluctuates substantially with time and space, and its effect on plant growth is generally non-linear. Therefore, errors in weather variables will have a large impact on model estimates that subsequently may lead to inaccurate results and conclusions and inappropriate decisions, such as investment decisions that depend on good understanding of potential biomass yields and other attributes (Stallings, 1961; Semenov and Porter, 1995; Tao et al., 2009; Van Wart et al., 2013). Therefore, the choice of a weather data source and its data quality are critical to obtain accurate biomass estimates to be used in other models.

Models can use either observed weather data collected at meteorological stations or gridded weather data, that is distributed weather estimates based on interpretations of weather measured elsewhere. When models operate at regional scale, gridded weather data sets are commonly used because they offer full spatial coverage of the region of interest with data for 
each grid cell, and there may be insufficient density of weather stations to represent adequate spatial weather patterns over large areas (Van Wart et al., 2013). Gridded weather datasets are generally produced using (1) interpolation techniques to interpolate observational weather data and topographic characteristics or (2) data modeling and assimilation techniques (Eum et al., 2014) that attempt to model changes in weather across a region based on local topographical, land cover, and other attributes. As grid-point associated weather values in gridded weather datasets are for the most part not observational data, there are uncertainties in these values, and the degree of uncertainty varies with the source of the weather data and the assimilation technique used to generate the gridded data. Thus, quantifying the uncertainties in gridded data sets compared to observational data is important to understand their impact on model yield and production estimates.

Given the significance of weather data quality on biomass estimates, this study was conducted with two specific objectives: (1) to evaluate weather data quality of four commonly used high resolution gridded weather datasets available for the U.S.: the NARR (North American Regional Reanalysis), NLDAS (North American Land Data Assimilation System), PRISM (Parameter-elevation Relationships on Independent Slopes Model), and Daymet and 2) to quantify the impact of uncertainty in weather variables on biomass yield estimates of SRWC hybrid poplar at specific site and regional levels. Hereafter for conciseness, we refer to gridded weather datasets as gridded data. In this study, hybrid poplar is chosen because it is a widely studied SRWC for biofuel production and a coppiced-based growth model (Hart, et al., 2015) has already been developed to predict yields as part of a larger optimization modeling framework (Bandaru et al., 2015).

\section{Materials and methods}


We used observed weather data from five flux tower sites as reference data to assess the uncertainty in five weather variables of the various gridded data sets. Weather variables include 1) minimum air temperature $\left.\left(T_{\min }\right) 2\right)$ maximum air temperature $\left.\left(T_{\max }\right) 3\right)$ solar radiation $\left.(S R) 4\right)$ precipitation (Precip) and 5) dew point temperature $\left(\mathrm{T}_{\mathrm{d}}\right)$. We simulated biomass estimates of hybrid poplar cultivated with a 3-year rotation period at flux tower site and regional levels using a modification of the Physiological Principles in Predicting Growth (3-PG) poplar model (Landsberg and Waring, 1997; Landsberg, et al., 2003; Hart et al., 2015). Site-level simulations were carried out using gridded data and weather data at the flux tower sites, and the differences in the model estimates were used to determine relative uncertainty in the biomass yield estimates. Regional simulations were based on the gridded data only, and these estimates were used to determine differences in spatial patterns and total biomass estimates with use of the various gridded datasets.

\subsection{Study region}

Regional simulations were implemented over croplands and rangelands in the Columbia Plateau region that extends across the states of Washington, Oregon and Idaho covering 260,000 km² (Fig. 1). This region within the Pacific Northwest of the U.S. is renowned for diverse landscape features and major agricultural land use and is already under investigation for its potential in producing biofuels and other bio-based products. The elevation in the region ranges from 60 to 1500 meters above sea level. Most of the region is characterized by a semi-arid climate as 57 percent of the region receives less than $380 \mathrm{~mm}$ annual precipitation (Vaccaro et al., 2015). Average annual precipitation varies with geographical location, ranging from $177 \mathrm{~mm}$ in the central part of the region to more than $1000 \mathrm{~mm}$ in the surrounding mountains (Vaccaro et 
al., 2015). The average annual precipitation of the entire region is $430 \mathrm{~mm}$ and the average annual temperature ranges from 4 to $14{ }^{\circ} \mathrm{C}\left(40-57^{\circ} \mathrm{F}\right)$.

\subsection{Weather databases}

\subsubsection{Observational data}

We selected flux tower sites as opposed to weather stations because observations at weather stations are included as input to generate some of the gridded datasets (e.g. PRISM and Daymet) and therefore do not constitute as an independent source for comparison. Five flux tower sites were selected for reference data to evaluate and quantify the biases in gridded datasets. We chose sites that are situated on either grasslands or croplands, and have weather data for at least four years, and have all the weather variables required for model simulations. We discarded flux tower sites located on forest land due to perceived influences of forest cover on weather station data. The selected flux tower sites include 1) Audubon Research Ranch, AZ 2) Bondville, IL 3) Fort Peck, MT 4) Mead Rainfed, NE 5) Varia Ranch, CA. Details of the sites are listed in Table 1.

\subsubsection{Gridded weather databases}

There are a number of gridded datasets covering the U.S. However, most are characterized by coarse spatial resolution $\left(>0.5^{\circ}\right)$. In this study, we evaluated high resolution gridded data that have a spatial resolution less than $0.5^{\circ}$ commonly used in terrestrial ecosystem modeling (Zhang et al., 2010; Bandaru et al., 2013; Hart et al., 2015). The details of the selected gridded datasets are listed in Table 2. While NARR and NLDAS are primarily produced based on atmospheric models and assimilation techniques, PRISM and Daymet datasets are generated mainly based on spatial interpolation techniques using weather observations from various monitoring networks as noted in the following. 


\section{NARR (North American Regional Reanalysis)}

The NARR dataset provides regional scale (approximately $32 \mathrm{~km}$ ) gridded data with 3hour temporal resolution covering from 1979 to the present. The NARR data are produced using the National Centers for Environmental Prediction (NCEP) Eta model, a mesoscale weather forecasting atmospheric model (Mesinger, 2006) along with the Regional Data Assimilation System (RDAS) (DiMego et al., 1992). RDAS uses data from various sources (e.g. outputs from the NCAR/NCEP Global reanalysis) (Mesinger, 2005) and integrates them to produce fine spatial and temporal resolution estimates based on a three-dimensional variational analysis scheme (3DVAR) and statistical interpolation (Kalnay et al., 1996). NARR provides many weather variables including air temperature, precipitation, shortwave radiation and relative humidity.

2. NLDAS (North American Land Data Assimilation System)

NLDAS is a weather forcing model that downscales NARR weather parameters and adjusts weather variables to account for the vertical difference between the NARR and NLDAS fields. NLDAS produces weather variables at fine spatial (1/8-degree, approximately $12 \mathrm{~km})$ and temporal resolution (1-hour) (Cosgrove et al., 2003). In addition, it corrects biases in shortwave radiation using Geostationary Operational Environmental Satellite (GOES) data (Pinker et al., 2003). NLDAS precipitation data are constructed by taking daily gauge-based precipitation data and disaggregating to hourly resolution using radar data (Xia, 2012).

\section{PRISM (Parameter-elevation Relationships on Independent Slopes Model)}

PRISM generates gridded data of four weather variables $\left(\mathrm{T}_{\max }, \mathrm{T}_{\min }\right.$, Precip, and $\left.\mathrm{T}_{\mathrm{d}}\right)$ at two spatial resolutions (800 $\mathrm{m}$ and $4 \mathrm{~km}$ ) and two temporal resolutions (daily and monthly) (Abatzoglou, 2013). PRISM uses gridded elevation data and computes a climate-elevation 
regression for each grid cell using observed data of nearby stations. Each station included in the regression is weighted based on similarity in physiographic characteristics (Daly. 2008). The data coverage is from 1979 to the present.

\section{Daymet}

The Daymet gridded data are produced at $1 \mathrm{~km}$ spatial resolution on daily time steps. Daymet takes daily weather station observations including $\mathrm{T}_{\min }, \mathrm{T}_{\max }$, and Precip and uses gridded elevation data to generate estimates for each gridded pixel based on a spatial convolution of a truncated Gaussian filter interpolation method (Thornton et al., 1997). Daymet produces downward shortwave radiation by using the MTclim algorithm (Thornton and Running, 1999). The data were available from 1979-2014.

\subsection{3-PG poplar model}

For SRWC biomass yield simulations, recently various models have been developed and applied with good result at field sites with $\mathrm{r}^{2}$ values ranging from 0.58-0.91 (Amichev et al., 2011; Tallis et al., 2013). One such model used for forest growth simulations is the Physiological Principles in Predicting Growth (3-PG) model (Landsberg and Waring, 1997). The 3-PG model has simple representations of general biophysical processes that control plant growth and requires limited input data (Landsberg and Waring, 1997). As such, the model can easily be applied over large regions and for any forest species with little modification of parameters. Due to ease of application, 3-PG has been frequently used for modeling the growth of forests and plantations (Landsberg et al., 2003; Dye et al., 2004; Almeida et al., 2010). One of the unique characteristics of SRWC, however, is coppicing, or harvesting trees near ground level and allowing the trees to resprout for subsequent growth and harvest, a process that can be repeated multiple times over the life of the tree plantation. The original 3-PG model does not account for 
coppicing and could not model this important aspect of SRWC grown for biomass. To model growth and biomass yields of SRWC with coppice management, the original 3-PG model was modified to include a coppicing and regrowth subroutine and is referred to as the 3-PG-Coppice model (Hart et al., 2015). This revised model was used here to estimate poplar biomass.

\subsection{Data preparation}

Observational data at flux tower sites were obtained from the Ameriflux website (http://ameriflux.lbl.gov/). We chose level-IV daily data as the set was gap filled and quality controlled. For consistent comparisons, both observational and gridded data were aggregated to a monthly time scale and converted to the same units. Weather data of each gridded dataset associated with each flux tower were extracted to measure the uncertainty in gridded weather variables and to use in site level 3-PG-Coppice simulations. For regional simulations, 11 years of data from 1996 to 2006 covering the Columbia Plateau region were obtained for each gridded data source. Because 3-PG model uses monthly time steps, gridded data sets with other than monthly time resolution (i.e. NARR, NLDAS and Daymet) were aggregated.

\subsection{Quantification of uncertainty in gridded datasets}

We used a bias metric to measure the uncertainty in weather variables of each gridded data source. Bias was estimated as the difference between the gridded product value and weather station value (Equation 1). Plant growth mainly occurs during the growing season (March to October) and weather uncertainty during this period is critical to understand uncertainty in biomass yield estimation. Thus, we calculated average bias in each weather variable over the growing season and averaged over the available years.

$$
\text { bias }=\frac{1}{n} \sum_{i=1}^{n}\left(W_{g}-W_{o}\right)
$$

where bias $=$ mean bias (units) 


$$
\begin{aligned}
& \mathrm{n}=\text { total available monthly data for all stations } \\
& \mathrm{i}=\text { index for a unique station, year, and month combination } \\
& \mathrm{W}_{\mathrm{g}}=\text { gridded data products } \\
& \mathrm{W}_{\mathrm{o}}=\text { flux tower observed value }
\end{aligned}
$$

\subsection{Model simulations}

We implemented 3-PG-Coppice simulations at flux tower sites and at the regional scale. The site-level simulations based on weather observations were considered as reference simulations and resulting biomass estimates were used as reference values to quantify the bias in biomass estimates based on weather data from gridded data sources. Regional simulations were used to understand the differences in spatial patterns and differences in total biomass between the gridded databases.

The 3-PG-Coppice model requires four different sets of parameters including 1) weather variables $\left(\mathrm{T}_{\max }, \mathrm{T}_{\min }\right.$, precip, $\mathrm{SR}, \mathrm{Tdmean}\left(\mathrm{T}_{\mathrm{d}}\right)$ ) 2 ) soil characteristics (soil water holding capacity, and two parameters summarizing soil types or compositions) 3) plant growth parameters 4) management regime (e.g. irrigation and fertility level). To assess the impact of gridded weather inputs, other inputs and parameters of the model were kept fixed for all simulations. For soil information, we obtained the inputs from the Soil Survey Geographic (SSURGO) database (http://websoilsurvey.nrcs.usda.gov/). Plant growth parameters for hybrid poplar were obtained from Hart et al., 2015. We have used growth parameters of fast growing interspecific inter-American hybrid clone (Populus trichocarpa X P. deltoides) with stock density of 3857 plants per hectare. Simulations were based on no irrigation (rainfed only) and medium fertility level. 
Hybrid poplar plantations are typically managed for more than a decade before replanting. To represent a reasonable growing period, simulations were run for 11 years using weather data from 1996-2006 with 4 coppicing cycles, harvested every three years except the first harvest that was assumed to occur after 2 years typical of current planting and harvesting regimes. For site level simulations, missing years for the flux tower data were replaced with monthly averages from available years. To be consistent with analysis of the weather biases, gridded data were processed in a way similar to the flux tower data. For regional level simulations, gridded weather data for all 12 years were utilized and simulations were carried out at $1 \mathrm{~km}$ spatial resolution. Coarse resolution weather variables were disaggregated to $1 \mathrm{~km}$ resolution using a bilinear interpolation method.

\section{Results}

\subsection{Uncertainty in gridded weather datasets}

Average biases in monthly weather variables of gridded data with corresponding mean observations from the five flux tower sites are presented in Fig. 2. Bias in $\mathrm{T}_{\max }$ and $\mathrm{T}_{\min }$ vary with the month of the growing season and gridded data sources, ranging from -0.8 to $3{ }^{\circ} \mathrm{C}$. Results show PRISM to have the lowest bias in $\mathrm{T}_{\max }$ and $\mathrm{T}_{\min }$ with a growing season average bias of $0.3{ }^{\circ} \mathrm{C}$ and $-0.3{ }^{\circ} \mathrm{C}$, respectively, followed by Daymet with average bias of $0.8{ }^{\circ} \mathrm{C}$ and $0.6{ }^{\circ} \mathrm{C}$. NLDAS and NARR were found to have higher bias in temperature variables than PRISM and Daymet (Fig. 2). NARR had the highest average $\mathrm{T}_{\max }$ bias $\left(0.9^{\circ} \mathrm{C}\right)$, followed by NLDAS at 0.8 ${ }^{\circ} \mathrm{C}$, while NLDAS had the highest average $\mathrm{T}_{\min }$ bias of $2.6^{\circ} \mathrm{C}$, followed by NARR at $2.1^{\circ} \mathrm{C}$. Results indicate that all data sources underestimated dew point temperature except NARR, with biases ranging from $1{ }^{\circ} \mathrm{C}$ to $-6^{\circ} \mathrm{C}$ depending on the data source and month of the season. NARR underestimated dew point temperature most of the months except for March, April and May. 
NLDAS was found to have the highest average bias $\left(-4.5^{\circ} \mathrm{C}\right)$ followed by Daymet $\left(-1.7^{\circ} \mathrm{C}\right)$, PRISM $\left(-0.6{ }^{\circ} \mathrm{C}\right)$, and NARR $\left(-0.4{ }^{\circ} \mathrm{C}\right)($ Fig. 2$)$. Results showed that biases in precipitation were considerably larger for all datasets and the degree of bias was not found to vary significantly among the data sources, with bias ranging from 4 to $18 \mathrm{~mm} \mathrm{month}^{-1}$ depending on the month of the growing season (Fig. 2). PRISM does not include shortwave radiation; therefore, biases were computed for Daymet, NARR and NLDAS (Fig. 2). Results indicated that NARR overestimated the shortwave radiation compared to the observed data while Daymet underestimated with negative bias, and this pattern was found to be consistent irrespective of the flux tower site (Fig. 2). The lowest average (averaged over all months) bias $\left(0.6 \mathrm{MJ} \mathrm{m}^{-2}\right)$ was observed for NLDAS, followed by Daymet $\left(-1.3 \mathrm{MJ} \mathrm{m}^{-2}\right)$ and NARR $\left(3.2 \mathrm{MJ} \mathrm{m}^{-2}\right)$. The bias in NARR for shortwave radiation was found to be substantially higher than in Daymet and NLDAS (2 and 5 times higher, respectively).

\subsection{Biomass estimates at flux tower sites}

Annualized biomass yields simulated at different flux tower sites based on all weather datasets are presented in Fig. 3. When model simulations were run with PRISM weather variables, NLDAS shortwave radiation was used as PRISM does not produce shortwave radiation. As opposed to other datasets, NLDAS shortwave radiation was chosen because of its least bias. Estimated biomass values at each site vary considerably depending on the weather data source. Annualized mean biomass yields modeled using the flux tower site data range from 8.4-18.0 Mg ha ${ }^{-1} \mathrm{yr}^{-1}$ depending on the site (Fig. 3). Gridded data-based biomass estimates were generally lower than flux tower weather based biomass values, except those with NARR data which were overestimated (Fig. 3). Biomass estimates with NLDAS were found to be considerably lower (5.3-13.5 $\mathrm{Mg} \mathrm{ha}^{-1} \mathrm{y}^{-1}$ ), than flux towers site weather data-based estimates followed by estimates using data from Daymet (6.4-15.8 $\left.\mathrm{Mg} \mathrm{ha}^{-1} \mathrm{y}^{-1}\right)$ and PRISM (7.7-19.4 Mg 
$\mathrm{ha}^{-1} \mathrm{y}^{-1}$ ) (Fig. 3). The NARR based biomass estimates of 10.4-25.6 $\mathrm{Mg} \mathrm{ha}^{-1} \mathrm{y}^{-1}$ (Fig. 3) were found to be substantially higher than tower based estimates. On average, NARR data resulted in 4.1 $\mathrm{Mg} \mathrm{ha}^{-1} \mathrm{y}^{-1}$ higher biomass yield than predicted from the observed weather data while NLDAS, Daymet and PRISM yielded 3.3, 1.2 and 0.3 $\mathrm{Mg} \mathrm{ha}^{-1} \mathrm{y}^{-1}$ lower biomass.

\subsection{Regional biomass estimates}

Regional biomass estimates based on all gridded datasets exhibited approximately identical spatial patterns with lower yields in the central part of the region and higher yields in the eastern and southern parts; however, the magnitude of the estimated biomass estimated values varied substantially with different gridded data sources (Fig. 4). The median regional biomass values based on NLDAS, NARR, Daymet, and PRISM data were 7.3 $\pm 0.9,9.7 \pm 3.7,7.9 \pm$ 1.6, and $8.3 \pm 1.8 \mathrm{Mg} \mathrm{ha}^{-1} \mathrm{y}^{-1}$, respectively (Fig. 5). NLDAS based biomass estimates were lower across the regions with lower variability compared to other estimates (Fig. 4 and 5). The NARR based biomass yields showed the highest variability in yields across the region with extreme high and low yield values, followed by PRISM, Daymet, and NLDAS based estimates (Fig. 5).

\section{Discussion}

Given the significance of gridded datasets in the spatial modeling of biomass estimation for bioenergy analyses, we evaluated four high resolution gridded datasets commonly used in agricultural and ecological studies (Adler et al., 2007; Zhang et al., 2010; Bandaru et al., 2013; Graves et al., 2016), to understand uncertainties in weather variables and their impact on biomass simulations of hybrid poplar.

The uncertainty analysis of the gridded datasets indicated that weather variables in all four are characterized by some degree of bias compared to the observed weather data at flux tower sites. In most cases, bias patterns were consistent, although flux tower sites were located widely 
across the U.S. Gridded datasets are typically created using modeling and interpolation techniques, which may not properly characterize topographic and land use features affecting the climate (Zhong and Fast, 2003; Miao et al., 2007; Van Wart et al., 2013). This can result in systematic errors in weather variables. Results suggest that the degree of uncertainty varies among the gridded datasets. PRISM and Daymet were found to have lower biases in most of the weather variables relative to NLDAS and NARR. This could be due in part to the higher spatial resolutions of Daymet and PRISM, and higher dependency on station weather observations (Daly et al. 2008; Abatzoglou, 2013; Eum et al., 2014). Similar to our findings, previous studies also noticed fewer biases in PRISM and Daymet compared to NARR data. The PRISM data were shown to have fewer biases compared to Daymet, which was also evident in earlier studies (Daly et al., 2008). PRISM data include local landscape features while Daymet is purely based on numerical interpolation which might explain higher bias in Daymet results compared to those using PRISM (Daly et al., 2008).

Individual weather variables affect one or more plant processes; therefore, bias in one variable may have a strong impact on simulated biomass. For instance, shortwave radiation directly affects the amount of biomass accumulated and indirectly affects evapotranspiration through affecting leaf area index (LAI) and stomatal conductance. NARR shortwave radiation was found to have large uncertainty in shortwave radiation, more than $30 \%$ bias compared to observational weather data at flux tower sites when averaged over all years. Earlier studies found a similar trend in NARR shortwave radiation (Schroeder et al., 2009). Apparently, bias correction in NLDAS using GOES radar data reduced the uncertainty substantially, to less than $5 \%$. Temperature variables in the models are used to determine growth limiting factors (i.e. temperature stress, number of frost days, and vapor pressure deficit (vpd)) (Landsberg and 
Waring, 1997). Nonhebel (1994) noticed that when temperature bias is greater than $1{ }^{\circ} \mathrm{C}$, crop yields were significantly reduced. Results suggested that biases in NARR and NLDAS $\mathrm{T}_{\min }$ are considerably higher (in most cases well above $1^{\circ} \mathrm{C}$ ) which may result in lower biomass yields. Dew point temperature is used along with $\mathrm{T}_{\max }$ and $\mathrm{T}_{\min }$ variables to calculate vpd. An increase in vpd was found to negatively affect photosynthetic efficiency (Day, 2000). Hence, bias in Td will indirectly impact the biomass predictions. Biases in Td were found to be less than $10 \%$ in all gridded datasets except in NLDAS (negative bias greater than 30\%). High bias in NLDAS Td could be attributed to biases in NLDAS specific humidity, which was noticed in earlier studies to have large uncertainty (Luo et al., 2003). Under rainfed conditions, U.S. precipitation is considered as the most limiting factor for plant growth and significantly influences biomass yields (Hoogenboom, 2000). Precipitation was found to be overestimated in all datasets, and this could be attributed to several factors including errors in rain gauge data and interpolation methods (Tao et al., 2009).

Biomass estimates based on PRISM weather with NLDAS shortwave radiation were found to have the lowest bias (-1.5\%), followed by Daymet (-9.9\%), NLDAS (-27.7\%), and NARR (45.0\%). These results suggest that PRISM with NLDAS shortwave radiation would produce more reasonable biomass values. The overall uncertainty in biomass estimates depends on bias in multiple variables while bias in individual variables can have large impact. For example, precipitation and solar radiation were overestimated in all datasets, but biomass yields were underestimated with all except NARR because of the interaction with other variables (Fig, 3). With NARR data, the effect of a large bias in solar radiation substantially impacted biomass yields, although there may be an interaction effect. 
It is important to note that gridded datasets may not be useful for location specific biomass estimates as gridded weather databases are not meant to represent location-specific conditions. However, comparison of site level biomass estimates is to emphasize the bias patterns with gridded weather datasets on biomass estimates. Results of regional simulations indicate that regional climate conditions would play significant role on how the biases in gridded weather variables affects regional biomass estimates. For instance, the central part of the region is dry with low annual precipitation while the eastern part is characterized by high annual rainfall. High bias in NARR shortwave radiation affected the yields in the central and eastern parts differently. Dry weather with high radiation bias led to poor growing conditions and extremely low yield estimates in the central region, while wet conditions in the eastern part with high radiation bias resulted in good growing conditions and high yield estimates.

Biomass yield is a fundamental element in assessing total bioenergy potential and to understand the prospects for energy crops to be adopted in a given region. Spatial discrepancies in biomass yields caused by biases in weather variables of gridded datasets may lead to inconsistent bioenergy estimates, which subsequently may lead to erroneous conclusions regarding bioenergy design capacity and economic feasibility. For instance, NLDAS, NARR, Daymet, and PRISM resulted in total annual biomass production of 47.4, 58.3, 51.2, and 53.9 Tg on the croplands and rangelands in the study region, with a biofuel potential of 4.3, 5.3, 4.6, and 4.9 Gigaliters (1128, 1386, 1217, and 1282 million gallons) of jet fuel per year based on a conversion yield of $90 \mathrm{~L} \mathrm{Mg}^{-1}$ dry weight (23 gallons per dry ton) of biomass reported by Hayward et al. (2015), a 23\% variation over the range when using biomass estimated from the various gridded data sources. 
Similarly, the breakeven price to cover production costs of hybrid poplar $\left(\$ 740 \mathrm{ha}^{-1} \mathrm{y}^{-1}\right)$ varies ranging from $\$ 86-\$ 105 \mathrm{Mg}^{-1}$ dry biomass depending on the weather data source to determine biomass. The production costs are based on observed input costs at a demonstration poplar plantation site in Hayden, Idaho. The breakeven price is an important economic parameter for poplar adoption by growers. As such, error in breakeven price arising from bias in biomass estimates will lead to incorrect decisions based on the perceived economic implications of poplar cultivation. Based on this study, it is evident that each weather dataset provides different outcomes regarding the bioenergy and economic potentials of short rotation woody crops. . Among the gridded datasets studied here, PRISM and Daymet appear to yield lower differences compared to flux tower estimates. Accounting for uncertainties in biomass estimates resulting from gridded datasets is particularly important when using them in energy and economic analyses for the purposes of investment and other deployment decisions.

\section{Acknowledgments}

The authors gratefully acknowledge the support of the United States Department of Agriculture National Institute of Food and Agriculture (USDA-NIFA). The work reported here was conducted under Agriculture and Food Research Initiative (AFRI) Competitive Grant Number 2011-68005-30407. The authors would like to extend gratitude to the anonymous reviewers for their valuable comments and remarks. 


\section{References}

Abatzoglou J (2013) Development of gridded surface meteorological data for ecological applications and modelling. International Journal of Climatology, 33, 121-131.

Adler PR, Grosso S, Parton W (2007) Life cycle assessment of net greenhouse-gas flux for bioenergy cropping systems. Ecological Applications, 17, 675-691.

Allen D, Mckenney D, Yemshanov D, Fraleigh S (2013) The economic attractiveness of short rotation coppice biomass plantations for bioenergy in Northern Ontario. Forestry Chronicle, 89, 66-78.

Almeida A, Siggins A, Batista T, Beadle C, Fonseca S, Loos R (2010) Mapping the effect of spatial and temporal variation in climate and soils on Eucalyptus plantation production with 3-PG, a process-based growth model. Forest Ecology and Management, 259, 17301740 .

Amichev B, Hangs R, Van Rees K (2011) A novel approach to simulate growth of multi-stem willow in bioenergy production systems with a simple process-based model (3-PG). Biomass \& Bioenergy, 35, 473-488.

Bandaru V, Izaurralde R, Manowitz D, Link R, Zhang X, Post W (2013) Soil Carbon Change and Net Energy Associated with Biofuel Production on Marginal Lands: A Regional Modeling Perspective. Journal of Environmental Quality, 42, 1802-1814.

Bandaru V, Parker N, Hart Q, Jenner M, Yeo B, Crawford J, Li Y, Tittmann P, Rogers L, Kaffka S, Jenkins B. 2015. Economic sustainability modeling provides decision support for assessing hybrid poplar-based biofuel development in California. California Agriculture, 69, 171-176.

Buchholz T, Volk T (2011) Improving the Profitability of Willow Crops-Identifying Opportunities with a Crop Budget Model. Bioenergy Research, 4, 85-95.

Cosgrove B, Lohmann D, Mitchell K et al. (2003) Real-time and retrospective forcing in the North American Land Data Assimilation System (NLDAS) project. Journal of Geophysical Research-Atmospheres, 108, D22, 8842.

Daly C, Halbleib M, Smith J et al. (2008) Physiographically sensitive mapping of climatological temperature and precipitation across the conterminous United States. International Journal of Climatology, 28, 2031-2064.

Day M (2000) Influence of temperature and leaf-to-air vapor pressure deficit on net photosynthesis and stomatal conductance in red spruce (Picea rubens). Tree Physiology, 20, 57-63.

De La Torre Ugarte D, Ray D (2000) Biomass and bioenergy applications of the POLYSYS 
modeling framework. Biomass \& Bioenergy, 18, 291-308.

Deal M, Xu J, John R et al. (2014) Net primary production in three bioenergy crop systems following land conversion. Journal of Plant Ecology, 7, 451-460.

Deckmyn G, Laureysens I, Garcia J, Muys B, Ceulemans R (2004) Poplar growth and yield in short rotation coppice: model simulations using the process model SECRETS. Biomass \& Bioenergy, 26, 221-227.

DiMego GJ, Mitchell KE, Petersen RA et al. (1992) Changes to NMC's Regional Analysis and Forecast System. Weather and Forecasting, 7, 185-198.

Downing M, Graham R (1996) The potential supply and cost of biomass from energy crops in the Tennessee valley authority region. Biomass \& Bioenergy, 11, 283-303.

Dubuisson X, Sintzoff I (1998) Energy and CO2 balances in different power generation routes using wood fuel from short rotation coppice. Biomass \& Bioenergy, 15, 379-390.

Dye P, Jacobs S, Drew D (2004) Verification of 3-PG growth and water-use predictions in twelve Eucalyptus plantation stands in Zululand, South Africa. Forest Ecology and Management, 193, 197-218.

Egbendewe-Mondzozo A, Swinton S, Izaurralde C, Manowitz D, Zhang X (2011) Biomass supply from alternative cellulosic crops and crop residues: A spatially explicit bioeconomic modeling approach. Biomass \& Bioenergy, 35, 4636-4647.

English BC, Torre Ugarte Ddl, Walsh Me, Hellwinckel Cm, Menard Rj (2006) Economic Competitiveness of Bioenergy Production and Effects on Agriculture of the Southern Region. Journal of Agricultural and Applied Economics, 38, 389-402.

Eum H, Dibike Y, Prowse T, Bonsal B (2014) Inter-comparison of high-resolution gridded climate data sets and their implication on hydrological model simulation over the Athabasca Watershed, Canada. Hydrological Processes, 28, 4250-4271.

Graves R, Pearson S, Turner M (2016), Landscape patterns of bioenergy in a changing climate: implications for crop allocation and land-use competition. Ecological Applications, 26 $515-529$.

Hart Q, Tittmann P, Bandaru V, Jenkins B (2015) Modeling poplar growth as a short rotation woody crop for biofuels in the Pacific Northwest. Biomass \& Bioenergy, 79, 12-27.

Hayward JA, O'Connell DA, Raison J, Warden A, O'Connor M, Murphy HT et al. (2015) The economics of producing sustainable aviation fuels: a regional case study in Queensland, Australia. Global Change Biol Bioenergy, 7, 497-511. 
Hinchee M, Rottmann W, Mullinax L et al. (2009) Short-rotation woody crops for bioenergy and biofuels applications. In Vitro Cellular \& Developmental Biology-Plant, 45, 619629.

Hoffmann D, Weih M (2005) Limitations and improvement of the potential utilisation of woody biomass for energy derived from short rotation woody crops in Sweden and Germany. Biomass \& Bioenergy, 28, 267-279.

Hoogenboom G (2000) Contribution of agrometeorology to the simulation of crop production and its applications. Agricultural and Forest Meteorology, 103, 137-157.

Hoogwijk M, Faaij A, De Vries B, Turkenburg W (2009) Exploration of regional and global cost-supply curves of biomass energy from short-rotation crops at abandoned cropland and rest land under four IPCC SRES land-use scenarios. Biomass \& Bioenergy, 33, 2643.

Kalnay E, Kanamitsu M, Kistler R et al. (1996) The NCEP/NCAR 40-year reanalysis project. Bulletin of the American Meteorological Society, 77, 437-471.

Landsberg J, Waring R (1997) A generalised model of forest productivity using simplified concepts of radiation-use efficiency, carbon balance and partitioning. Forest Ecology and Management, 95, 209-228.

Landsberg J, Waring R, Coops N (2003) Performance of the forest productivity model 3-PG applied to a wide range of forest types. Forest Ecology and Management, 172, 199-214.

Luo L, Robock A, Mitchell K et al. (2003) Validation of the North American Land Data Assimilation System (NLDAS) retrospective forcing over the southern Great Plains. Journal of Geophysical Research-Atmospheres, 108, 1-10.

McLaughlin SB, Adams Kszos L (2005) Development of switchgrass (Panicum virgatum) as a bioenergy feedstock in the United States. Biomass and Bioenergy, 28, 515-535.

Mesinger F, Dimego G, Kalnay E et al. (2006) North American regional reanalysis. Bulletin of the American Meteorological Society, 87, 343-360.

Miao JF, Chen D, Borne K (2007) Evaluation and Comparison of Noah and Pleim-Xiu Land Surface Models in MM5 Using GÖTE2001 Data: Spatial and Temporal Variations in Near-Surface Air Temperature. Journal of Applied Meteorology and Climatology, 46, 1587-1605.

Miao Z, Shastri Y, Grift T, Hansen A, Ting K (2012) Lignocellulosic biomass feedstock transportation alternatives, logistics, equipment configurations, and modeling. Biofuels Bioproducts \& Biorefining-Biofpr, 6, 351-362. 
Parker N, Tittmann P, Hart Q et al. (2010) Development of a biorefinery optimized biofuel supply curve for the Western United States. Biomass \& Bioenergy, 34, 1597-1607.

Pinker RT, Tarpley Jd, Laszlo I et al. (2003) Surface radiation budgets in support of the GEWEX Continental-Scale International Project (GCIP) and the GEWEX Americas Prediction Project (GAPP), including the North American Land Data Assimilation System (NLDAS) project. Journal of Geophysical Research: Atmospheres, 108, D22, 8844.

Rockwood D, Naidu C, Carter D et al. (2004) Short-rotation woody crops and phytoremediation: Opportunities for agroforestry? Agroforestry Systems, 61-2, 51-63.

Schmer M, Vogel K, Mitchell R, Perrin R (2008) Net energy of cellulosic ethanol from switchgrass. Proceedings of the National Academy of Sciences of the United States of America, 105, 464-469.

Schroeder T, Hember R, Coops N, Liang S (2009) Validation of Solar Radiation Surfaces from MODIS and Reanalysis Data over Topographically Complex Terrain. Journal of Applied Meteorology and Climatology, 48, 2441-2458.

Semenov MA, Porter Jr (1995) Climatic variability and the modelling of crop yields. Agricultural and Forest Meteorology, 73, 265-283.

Sims R, Venturi P (2004) All-year-round harvesting of short rotation coppice eucalyptus compared with the delivered costs of biomass from more conventional short season, harvesting systems. Biomass \& Bioenergy, 26, 27-37.

Stallings JL (1961) A Measure of the Influence of Weather on Crop Production. Journal of Farm Economics, 43, 1153-1160.

Tallis M, Casella E, Henshall P, Aylott M, Randle T, Morison J, Taylor G (2013) Development and evaluation of ForestGrowth-SRC a process-based model for short rotation coppice yield and spatial supply reveals poplar uses water more efficiently than willow. Global Change Biology Bioenergy, 5, 53-66.

Tao, F, Zhang Z, Liu J, Yokozawa M (2009) Modelling the impacts of weather and climate variability on crop productivity over a large area: a new super-ensemble-based probabilistic projection. Agriculture and Forest Meteorology, 149, 1266-1278.

Thornton P, Running S, White M (1997) Generating surfaces of daily meteorological variables over large regions of complex terrain. Journal of Hydrology. 190, $214-251$.

Thornton P, Running S (1999) An improved algorithm for estimating incident daily solar radiation from measurements of temperature, humidity, and precipitation. Agricultural and Forest Meteorology, 93, 211-228. 
Vaccaro JJ, Kahle Sc, Ely Dm, Burns Er, Snyder Dt, Haynes Jv, Olsen Td, Welch Wb, Morgan, Ds (2015) Ground water availability of the Columbia Plateau Regional Aquifer System, Washington, Oregon, and Idaho: U.S. Geological Survey Professional Paper 1817, 87.

Van Wart J, Grassini P, Cassman K (2013) Impact of derived global weather data on simulated crop yields. Global Change Biology, 19, 3822-3834.

Volk T, Abrahamson L, Nowak C, Smart L, Tharakan P, White E (2006) The development of short-rotation willow in the northeastern United States for bioenergy and bioproducts, agroforestry and phytoremediation. Biomass \& Bioenergy, 30, 715-727.

Xia Y, Mitchell K, Ek M et al. (2012) Continental-scale water and energy flux analysis and validation for the North American Land Data Assimilation System project phase 2 (NLDAS-2): 1. Intercomparison and application of model products. Journal of Geophysical Research-Atmospheres, 117, D3, D03109.

Zhang X, Izaurralde R, Manowitz D, West T, Post W, Thomson A, Bandaru V, Nichols J, Williams Jr (2010) An integrative modeling framework to evaluate the productivity and sustainability of biofuel crop production systems. Global Change Biology Bioenergy, 2, $258-277$.

Zhong S, Fast J (2003) An evaluation of the MM5, RAMS, and Meso-Eta models at subkilometer resolution using VTMX field campaign data in the Salt Lake Valley. Monthly Weather Review, 131, 1301-1322. 


\section{Tables}

Table 1. Details of flux tower sites providing reference observational weather data.

\begin{tabular}{|l|l|l|l|l|l|l|}
\hline Flux tower site & Abbrev. & Latitude & Longitude & land use & data length (y) & Elevation (m) \\
\hline Audubon Research Ranch, AZ & Aud & 31.59 & -110.5092 & Grasslands & 2003 to 2006 & 1469 \\
Bondville, IL & Bo1 & 40.01 & -88.2904 & Croplands & 1997 to 2006 & 219 \\
Fort Peck, MT & FPe & 48.30 & -105.1019 & Grasslands & 2001 to 2006 & 634 \\
Varia Ranch, CA & Var & 38.40 & -120.9507 & Grasslands & 2001 to 2007 & 129 \\
Mead Rainfed, NE & Ne3 & 41.18 & -96.4396 & Croplands & 2001 to 2006 & 363 \\
\hline
\end{tabular}

Table 2. Details of gridded weather datasets.

\begin{tabular}{|c|c|c|c|c|}
\hline $\begin{array}{l}\text { Gridded } \\
\text { data }\end{array}$ & $\begin{array}{l}\text { Spatial } \\
\text { resolution }\end{array}$ & $\begin{array}{l}\text { Temporal } \\
\text { resolution }\end{array}$ & Data length & Download Source \\
\hline $\begin{array}{l}\text { NARR } \\
\text { NLDAS } \\
\text { PRISM } \\
\text { Daymet }\end{array}$ & $\begin{array}{l}32 \mathrm{~km} \\
12 \mathrm{~km} \\
4 \mathrm{~km} \\
1 \mathrm{~km}\end{array}$ & $\begin{array}{l}\text { 3-hourly } \\
\text { 1-hourly } \\
\text { monthly } \\
\text { daily }\end{array}$ & $\begin{array}{l}\text { 1979-present } \\
\text { 1979-present } \\
\text { 1981-present } \\
\text { 1980-present }\end{array}$ & $\begin{array}{l}\text { ftp://ftp.cdc.noaa.gov/Datasets/NARR/ } \\
\text { http://disc.sci.gsfc.nasa.gov/hydrology } \\
\text { http://www.prism.oregonstate.edu/ } \\
\text { https://Daymet.ornl.gov/ }\end{array}$ \\
\hline
\end{tabular}




\section{Figures}

Fig. 1. Columbia Plateau study region used to implement the regional simulations.

Fig. 2. Comparison of bias in weather variables over the growing season (March to October) from gridded weather datasets. Bias shown in this figure calculated using equation 1.Primary Yaxis represents biases in gridded weather datasets while secondary Y axis represents measured weather data at flux towers used to estimate the biases.

Fig. 3. Comparison of simulated annualized biomass $\left(\mathrm{Mg} \mathrm{ha}^{-1} \mathrm{y}^{-1}\right)$ at flux tower sites based on observed weather data, and the NLDAS, NARR, Daymet and PRISM gridded datasets. Refer to Table 1 for flux tower sites.

Fig. 4. Simulated regional annualized biomass yield estimates $\left(\mathrm{Mg} \mathrm{ha}^{-1} \mathrm{y}^{-1}\right)$ of hybrid poplar on croplands and rangelands in the Columbia Plateau region, simulated using NLDAS, NARR, Daymet and PRISM gridded datasets.

Fig. 5. Box plot of hybrid poplar regional biomass yield estimates $\left(\mathrm{Mg} \mathrm{ha}^{-1} \mathrm{y}^{-1}\right)$ on croplands and rangelands in the Columbia Plateau region, simulated using NLDAS, NARR, Daymet and PRISM weather variables. Boxes extend to $75 \%$ and $25 \%$ quantiles. The whiskers extend from the box boundary to $1.5^{*}(75 \%$ quantile value $-25 \%$ quantile value). 


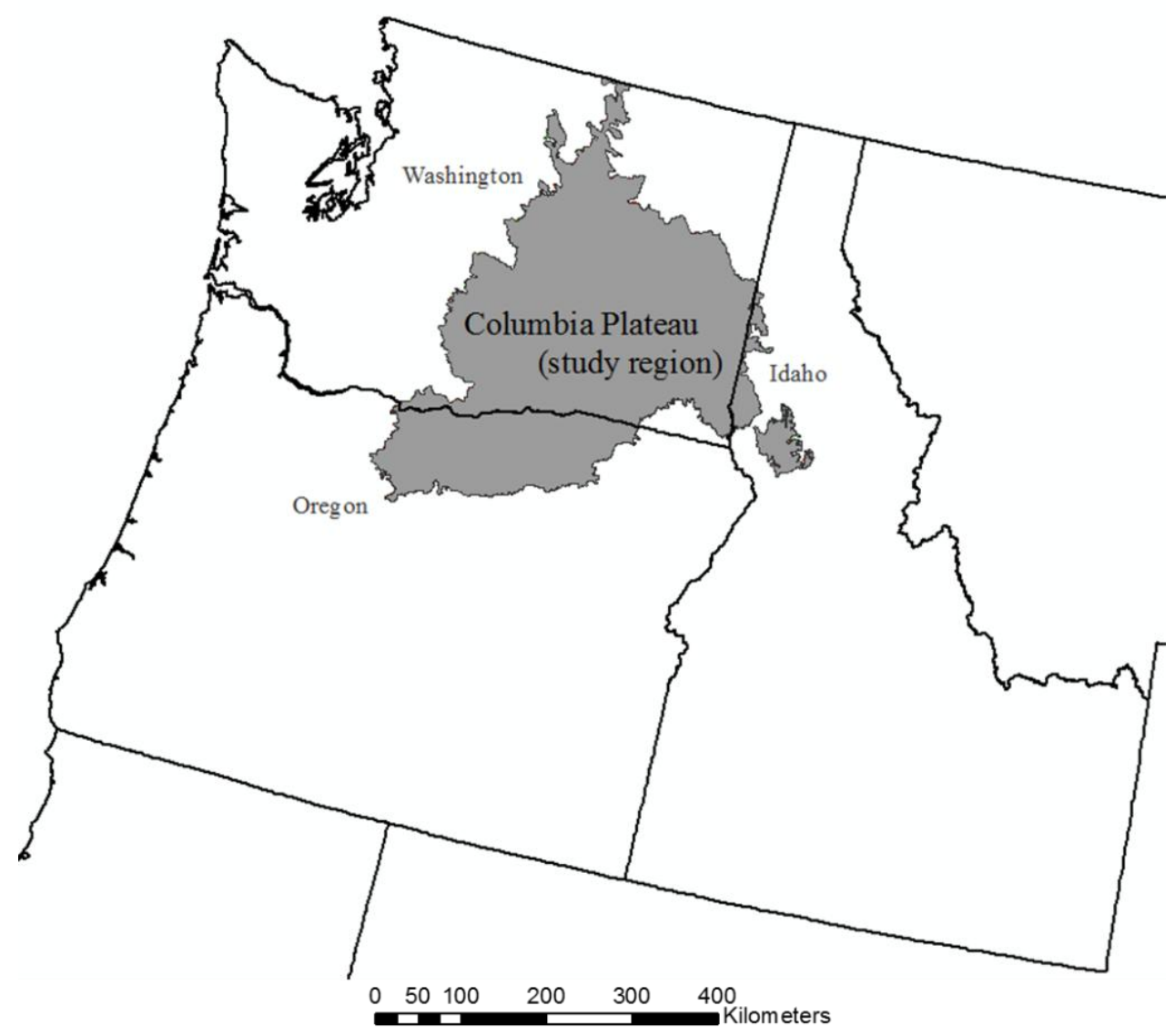

Fig. 1. Columbia Plateau study region used to implement the regional simulations. 


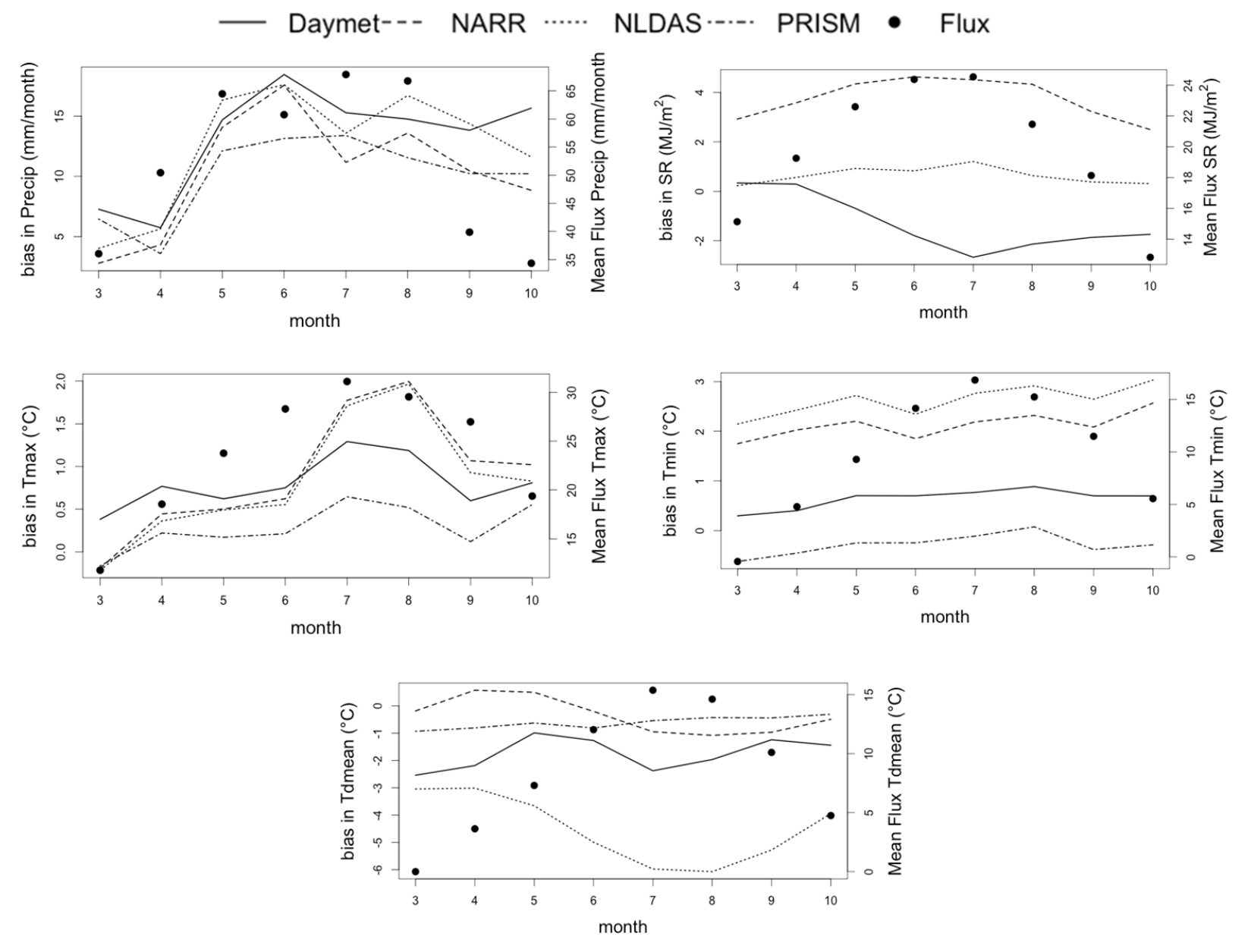

Fig. 2. Comparison of bias in weather variables over the growing season (March to October) from gridded weather datasets. Bias shown in this figure calculated using equation 1.Primary Yaxis represents biases in gridded weather datasets while secondary Y axis represents measured weather data at flux towers used to estimate the biases. 


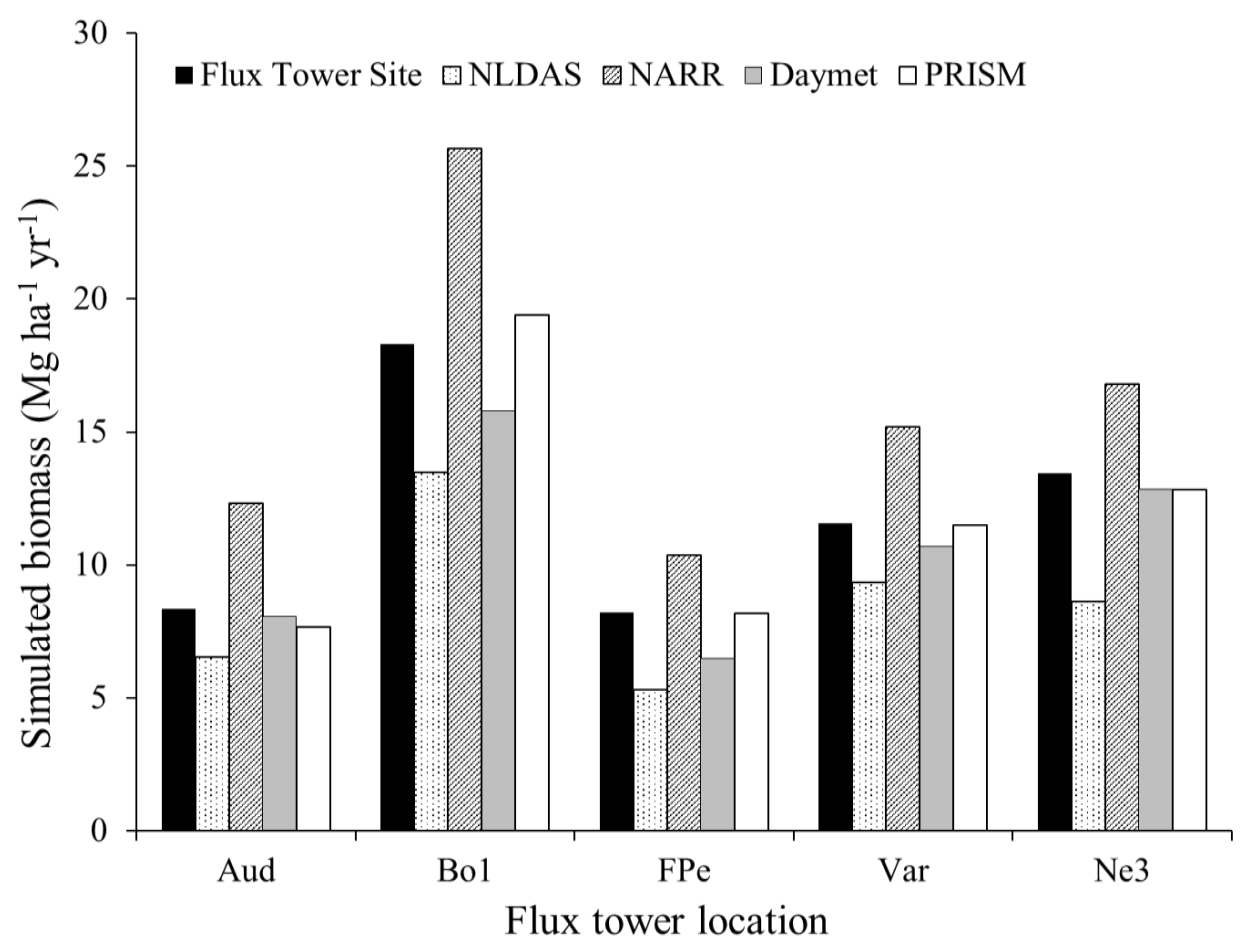

Fig. 3. Comparison of simulated annualized biomass $\left(\mathrm{Mg} \mathrm{ha}^{-1} \mathrm{y}^{-1}\right)$ at flux tower sites based on observed weather data, and the NLDAS, NARR, Daymet and PRISM gridded datasets. Refer to Table 1 for flux tower sites. 
a) NLDAS-based biomass estimates

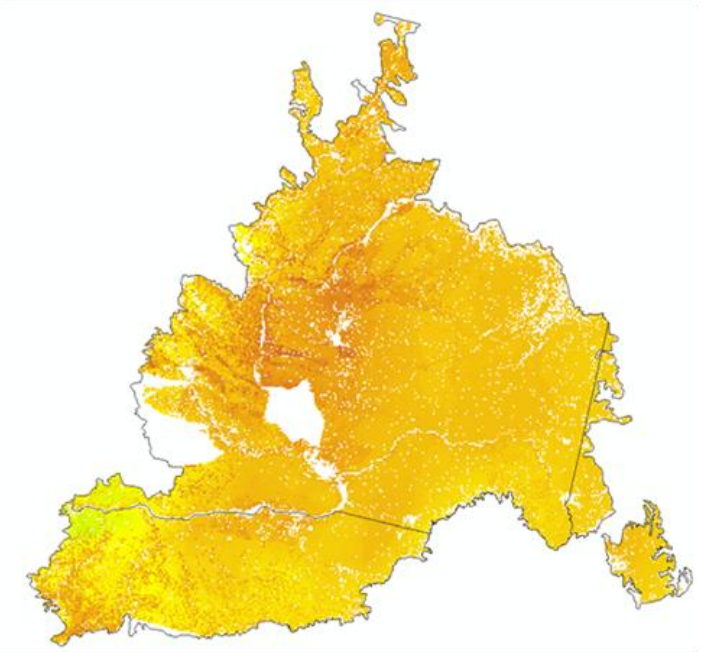

c) Daymet-based biomass estimates

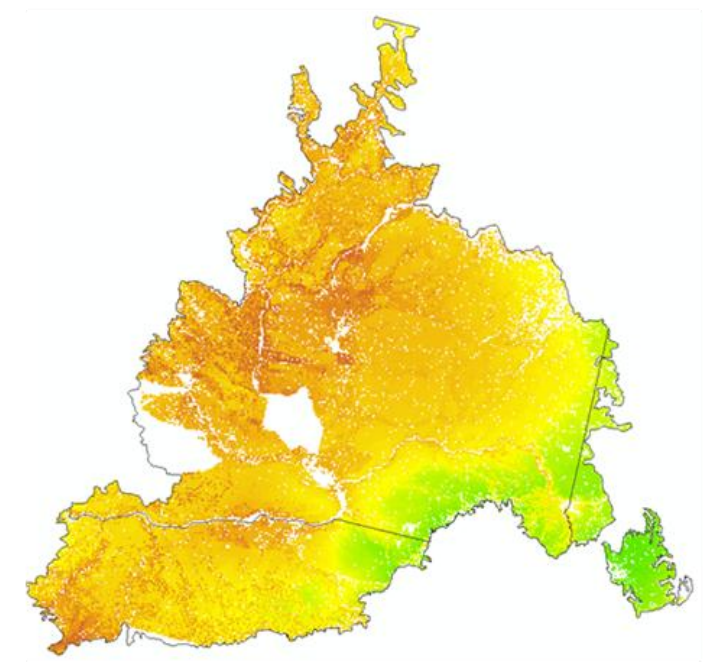

b) NARR-based biomass estimates

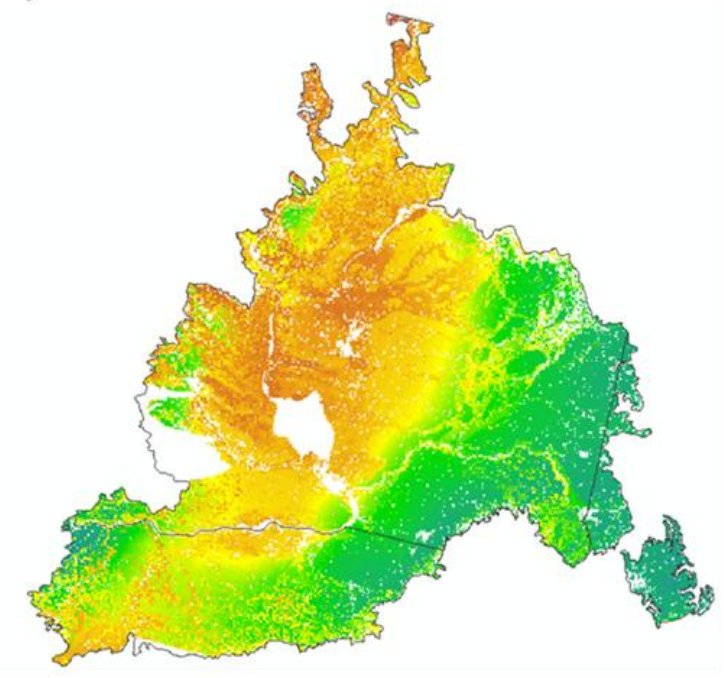

d) PRISM-based biomass estimates

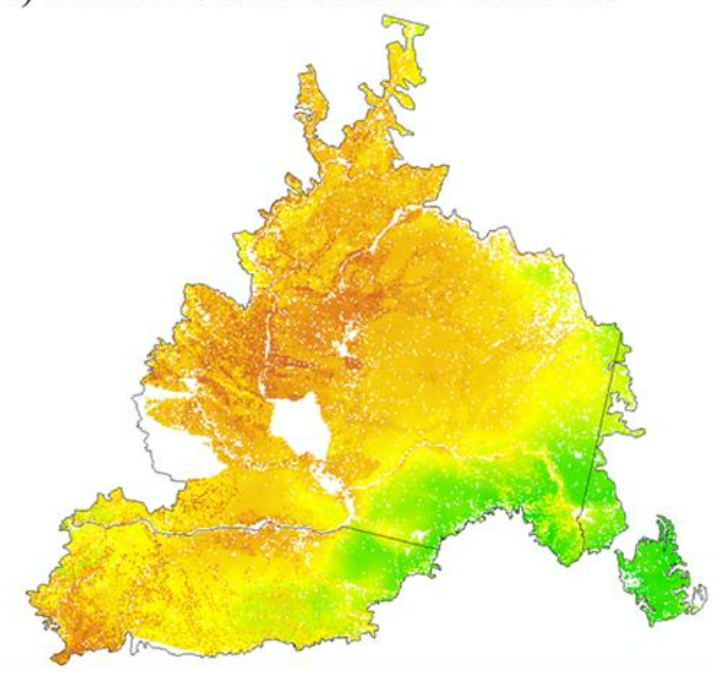

\section{Regional biomass $\left(\mathrm{Mg} \mathrm{ha}^{-1} \mathrm{yr}^{-1}\right)$}

\section{5}

Fig. 4. Simulated regional annualized biomass yield estimates $\left(\mathrm{Mg} \mathrm{ha}^{-1} \mathrm{y}^{-1}\right)$ of hybrid poplar on croplands and rangelands in the Columbia Plateau region, simulated using NLDAS, NARR, Daymet and PRISM gridded datasets. 


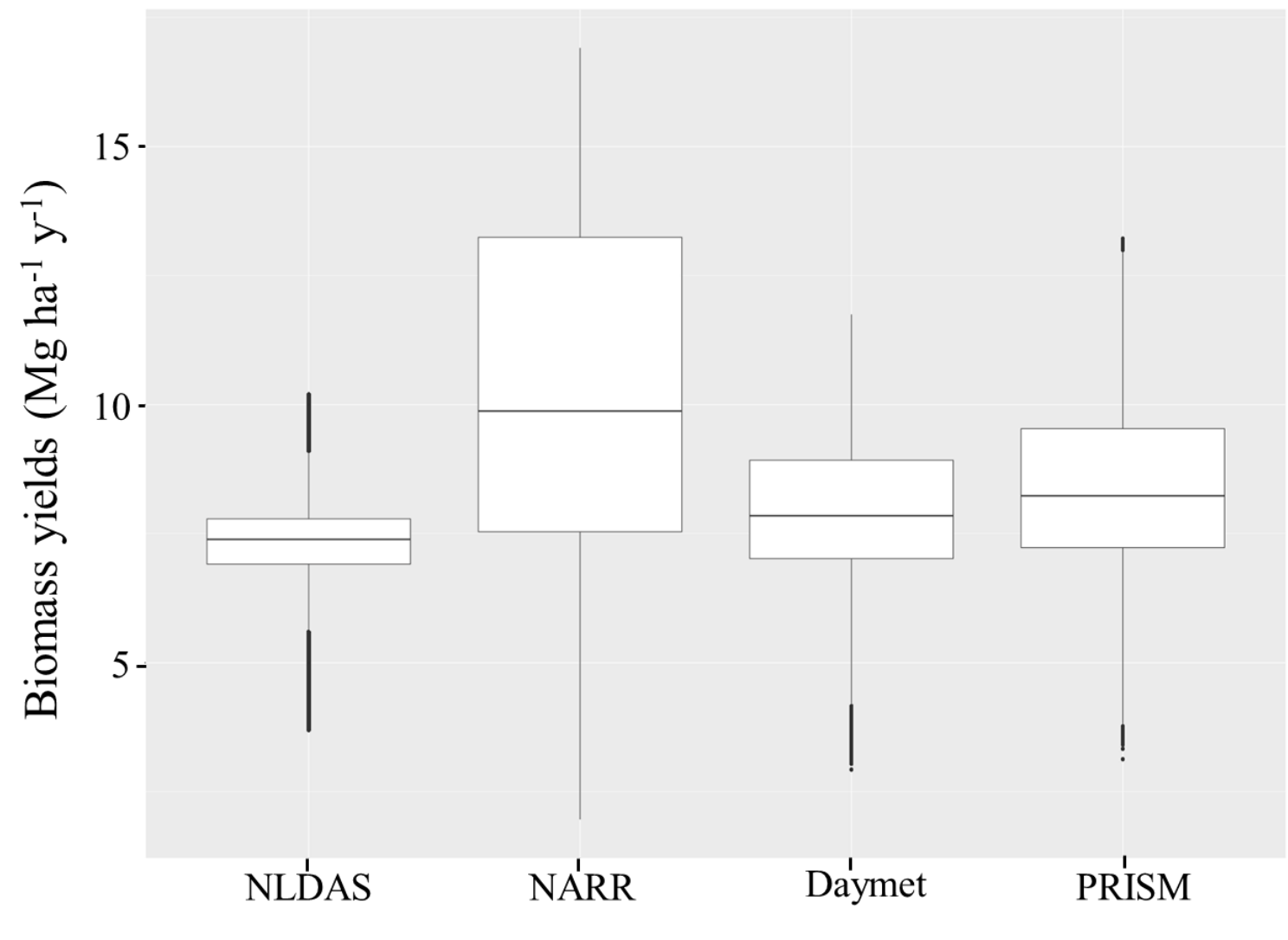

Gridded weather datasets

Fig. 5. Box plot of hybrid poplar regional biomass yield estimates $\left(\mathrm{Mg} \mathrm{ha}^{-1} \mathrm{y}^{-1}\right)$ on croplands and rangelands in the Columbia Plateau region, simulated using NLDAS, NARR, Daymet and PRISM weather variables. Boxes extend to $75 \%$ and $25 \%$ quantiles. The whiskers extend from the box boundary to $1.5^{*}(75 \%$ quantile value $-25 \%$ quantile value). 